\title{
The Study on Divide about Data Traffic Use between Mobile User Groups
}

\author{
Hongjae Lee ${ }^{1}$, Sang-wonKim² and Jong-Bae $\mathrm{Kim}^{3 *}$ \\ 1Department of IT Policy and Management, Graduate School of Soongsil \\ University, Seoul 156-743, Korea \\ 2 KT corp., Seoul, Korea \\ $3^{*}$ Graduate School of Software, Soongsil University, Seoul, 156-743, Korea \\ ${ }^{1}$ hjlee15314@daum.net, ${ }^{2}$ sangwon.kim@kt.com, ${ }^{3 *}$ kjb123@ssu.ac.kr
}

\begin{abstract}
Mobile data traffic has been rising rapidly caused by spreads and development of smart devices As a result, it brought a lot of changes throughbut gur life and usage pattern for mobile users, as well as mobile techlology advance and market alternation after data bandwidth growth and decline of mobile rate for data. Recently, the "Unlimited mobile tariff" has been released due to the severe competition between domestic mobile carriers, thus, the user of unlimited mobile aniff system inereases while users have mobile tariff cost relief. Also, the various devices are connected to each other everywhere in our life, not only past mobile phone andetablet. It is overly connected in one IoT era, then users of its services increases sharply, so that the data traffic of IoT devices are regarded as significant element to find out next mobile dota traffic usage and pattern study. The Goal of this study is to analyze the traffie of Korean mobile and wired line internet statistics by user group up the network development and mobile tariff progress. And it is required to find ont IoT devices market state and influence for mobile market based on empirical data and statistics in Koŕa.
\end{abstract}

Koywords Digital Divide, Mobile User-group, Mobile data traffic and Smartphone,
IoT

\section{Introduction}

Since Smartphone is released in market, it has brought tremendous alternation and influence around Global Telecom Market. Mobile Data Traffic is increasing drastically while a smartphone is regarded as an essential item of an individual's life. After mobile network has had huge movement from $3 \mathrm{G}$ network to $4 \mathrm{G}$ network, data speed has also inproved. It was available to provide $300 \mathrm{Mbps}$ as maximum bandwidth for mobile data service during change over into $4 \mathrm{G}$ Network, besides mobile Data charge for Telco service is sharply reduced. It was expanded for data traffic alongside voice call during $3 \mathrm{G}$ era, whereas voice call had been a major issue for a $2 \mathrm{G}$ network age. By the time, expensive volume rate data charge system was a general pattern for method of data service, caused by restricted network infrastructure. Most mobile B data traffic was tended to be consumed by Heavy user group. Afterwards, 4G Network era began in earnest while needs for large data spread for public with video or game. Particularly Korea has completed to establish the fastest $4 \mathrm{G}$ network infrastructure in the world. It results to the reduction of mobile service fee, though Bandwidth and Data speed are advanced. Moreover, unlimited data plan is on the telco market during severe competition

\footnotetext{
${ }^{3 *}$ Corresponding author. Tel. : +82-10-9027-3148.

Emailaddress: kjb123@ssu.ac.kr(Jong-Bae Kim).
} 
among major Telcos and handset shows remarkable progress caused by HW and SW technology development. It seems that various services appeared regardless of mobile internet connection restriction from area with network coverage improvement. Unlimited data plan is high ranked service for mobile users due to mitigation of mobile rate burden. As a result, mobile data traffic soared quickly during massive data contents consumption through a smartphone.

It is predicted that mobile data behavior is changed by the alternation of users from harsh and expensive condition into unrestricted and cheap mobile circumstance. Aim of this study is to find out mobile data consumption pattern as per user's behavior influenced by network development and transform of mobile fee. And it is looked for suggestion upon traffic analysis and data by real each user groups. Also it is dealt with how newly next IoT tech influences mobile data traffic usage.

\section{Related Works}

It is called as Digital Divide which is scientific field fór study of differentiation as social group with Internet information access and utilization. This terninology has been expressed with diverse worlds, such digital Gap, Infornation poverty and knowledge gap. It was focused on social structural inequality bring about by ICT progress. Recent articles are concentrated on qualitative and qualitative influence through social class and group about internet communication concerning (CT Digitalization provided emphasizing information gap about individual and social group after Internet economy structure governance stride has come (Jasoon Koe. 2007)

Digital divide is analyzed into diverse perspective. This concept is based on 3 elements. These 3 concepts are Opportunity Difference (Access of information), Utilization Difference (Information Use), and Acceptance Difference (Information notion).

Opportunity means that difference of Information access occurred from economical elements. It is also called Utilization Difference" which is a gap of information gadgets usage based on IT spreads. And there is "Acceptance Difference" which is information understanding notion.

The concept and charactefistios of Digital divide have been changing into every level of IT expans on yithin informatization tide. It shows the two aspects from S-Shaped time path of I.T spread. First aspect is gap of "Information Access and Information quantitative use" from early adaptation and Take-off period. Afterwards, it is found about gap of qualitative usage and access from Post Adaptation and Saturation period of S-Shaped time path figure. (Research of Information Gap Index and fact-finding, (NIA, 2014))

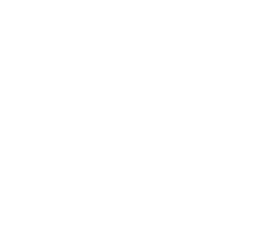




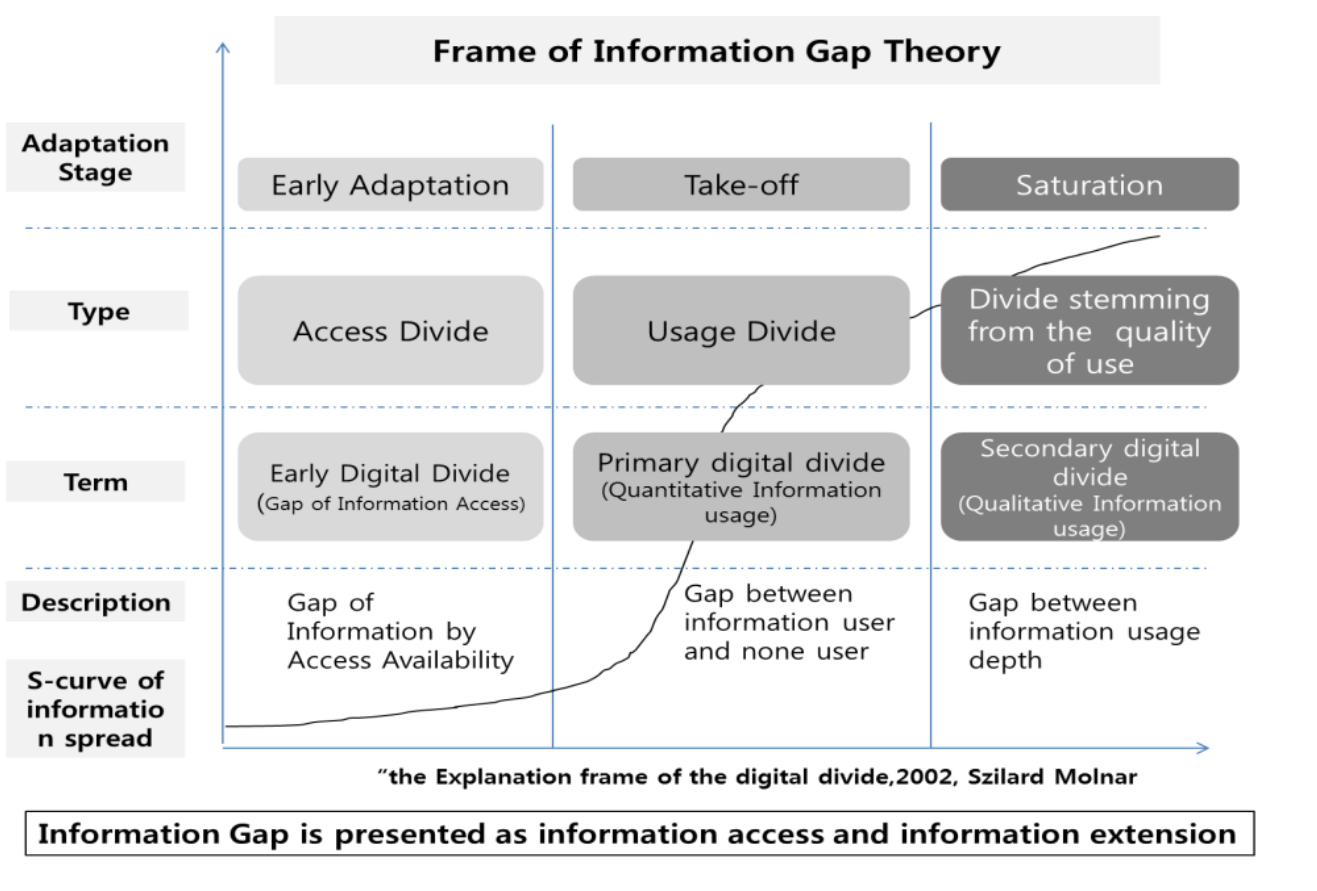

Figure 1. S-curve Digital Divide Concept (NIA, 2014)

Most studies are described as "Digital divide" about wired internet about a PC. However, this study is focused on "Digital Divided" of mobile data usage and gap of Mobile user group differences in Korean market based on the major tide of Mobile data with Smartphones. Previously, Information Gap theory shows that information access gap was key factor in entry stage, and then the difference between user and non-user groups is critical in midst phase finally Information Qualitative gap is getting significant in saturator phase.

South Korea is a leading country for most developed mobile network and wide coverage. Moreover, it is the highest internet usage in accordance with cheapest Data charge and lowest gap between groups. Korea also has the highest smartphone population users in the world. It regards as initial country for analyzation of mobile user groups gap in the matured mobile data market in Korea. This study delivers the insight about qualitative gap with Mobile divide by analyzing data tariff system which causes the phenomena that top $20 \%$ traffic is occupied by a heavy user group. And it is surveyed the portion of $10 \mathrm{~T}$ and each industries throughout up-to-date IoT market and broadband internet service traffic progress. Moreover, it has reviewed the new divide phenomenon appearance briefly.

\section{Trend of Mobile Heavy User Group Data Usage}

\subsection{Data}

This research is based on KT monthly data traffic statistics (KT occupies 30\% Market share in Korea mobile market) including broadband internet reference from Jan. 2013 to May, 2015. This statistic figures have an absolute disregard for personal information, because whole data is extracted Total Data usage and portions.

\subsection{Mobile Subscriber Number and Market Characteristics}

Korea is the first movement country for LTE service commercialization in 2011 after $3 \mathrm{G}$ service diffusion since 2003. It has scored thirty-eight million users among fifty-seven 
million mobile users and forty-one million lines smartphone users. Smartphone has become popular and a necessary item for people.

KT has led this trend and popularization since KT adopted i-phone in 2009 as pioneer. The 4G users rapidly increased from Jan, 2012 when 4G service launched. Its users overtook behind $3 \mathrm{G}$ subscribers by 2 years in Jan, 2014, and then traffic also passed over the $3 \mathrm{G}$ traffic. Today, $4 \mathrm{G}$ service is popular in public. The reason for $4 \mathrm{G}$ data traffic growth is its network bandwidth development and Data fee decline. Also Multimedia files upsurge and handset advancement also is one of the main reasons for $4 \mathrm{G}$ service surges. (Figure 1)

Network speed is provided as more than $1 \mathrm{Gbps}$ after Giga LTE tech introduction which is a combined LTE and Wi-Fi connection which is 3times faster Broad LTE Tech adoption rather than before. Another reason for Data usage explosion is price reduiction in data service. Especially, Unlimited Data tariff system which was released in April, 2014, which brings data traffic huge explosion. For instance, subscriber of unlimited data tariff increased into $14 \%$ of whole members of KT for few months. Subsequently, darta traffic of unlimited system also covers $53 \%$ of while data traffic nolv. It gives rise to data traffic burst.

Basically, share of traffic of flat rate system js a bit moreased due to unlimited data system traffic growth although the number of flat rate system user is a bit declined caused by middle-aged class who prefer the metered rated system, such as economic rate system. (Table 3)

Table 1. Progress of Total Data Traffic for $3 G$ / 4 G Service (Ministry of Science, ICT and Future Planning, Korea)

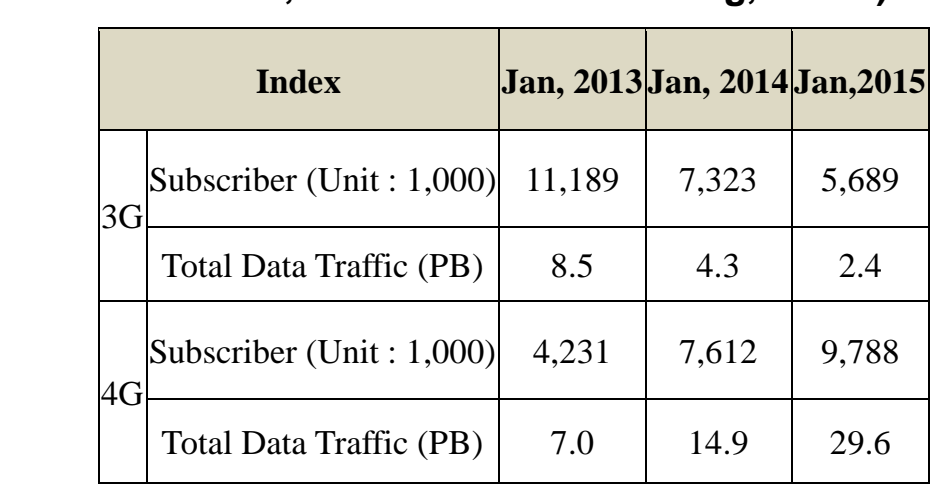

Table 2. Subscriber and Traffic Ratio for 4G Unlimited Data Service (KT)

\begin{tabular}{|c|c|c|c|}
\hline Classification & Jan, 2013 & Jan, 2014 & Jan,2015 \\
\hline Unlimited data service subscriber ratio & $0 \%$ & $1 \%$ & $14 \%$ \\
\hline Traffic of Unlimited data service ratio & $0 \%$ & $5 \%$ & $53 \%$ \\
\hline
\end{tabular}


Table 3. Ratio of 4G Data Service Traffic and Subscriber (KT)

\begin{tabular}{|c|c|c|c|}
\hline Classification & Jan, 2013 Jan, 2014 & Jan,2015 \\
\hline Subscriber of Flat rate service & $89 \%$ & $87 \%$ & $84 \%$ \\
\hline Traffic of Flat rate service & $94 \%$ & $94 \%$ & $95 \%$ \\
\hline
\end{tabular}

\subsection{Data Traffic Occupation Deviation of Mobile Heavy User}

It is analyzed about mobile data traffic statistics for $4 \mathrm{G}$ network. User group of Upper $20 \%$ increased drastically their traffic occupation after unlimited data tariff system launched in April 2014 by studying the data share with mobile heavy user group. They used to be stable and stationary before unlimited data system. It is found in [Figure 2]. It shows that none of progress for data traffic usage portion until January 2014, although Mobile network coverage has been expanded and speed is also advanced. On the other hand, Data usage occupation of heavy user is suddenly, increased rapidly after unlimited data tariff system release. The data occupation of upper 10 group has appeared $8.9 \%$ growth, $5 \%$ group increased $15.2 \%, 10 \%$ group is $14.4 \%$ growthand $20 \%$ group recorded $11.4 \%$ growth for mobile data usage occupation,

Also, it shows that data traffic portion is gradually up by heavy user group compared with 2013 about 3G network service from total mob(Re) user group (Figure 3). Especially, most data traffic $(99.7 \%)$ is made by upper $20 \%$ heavy user group in.

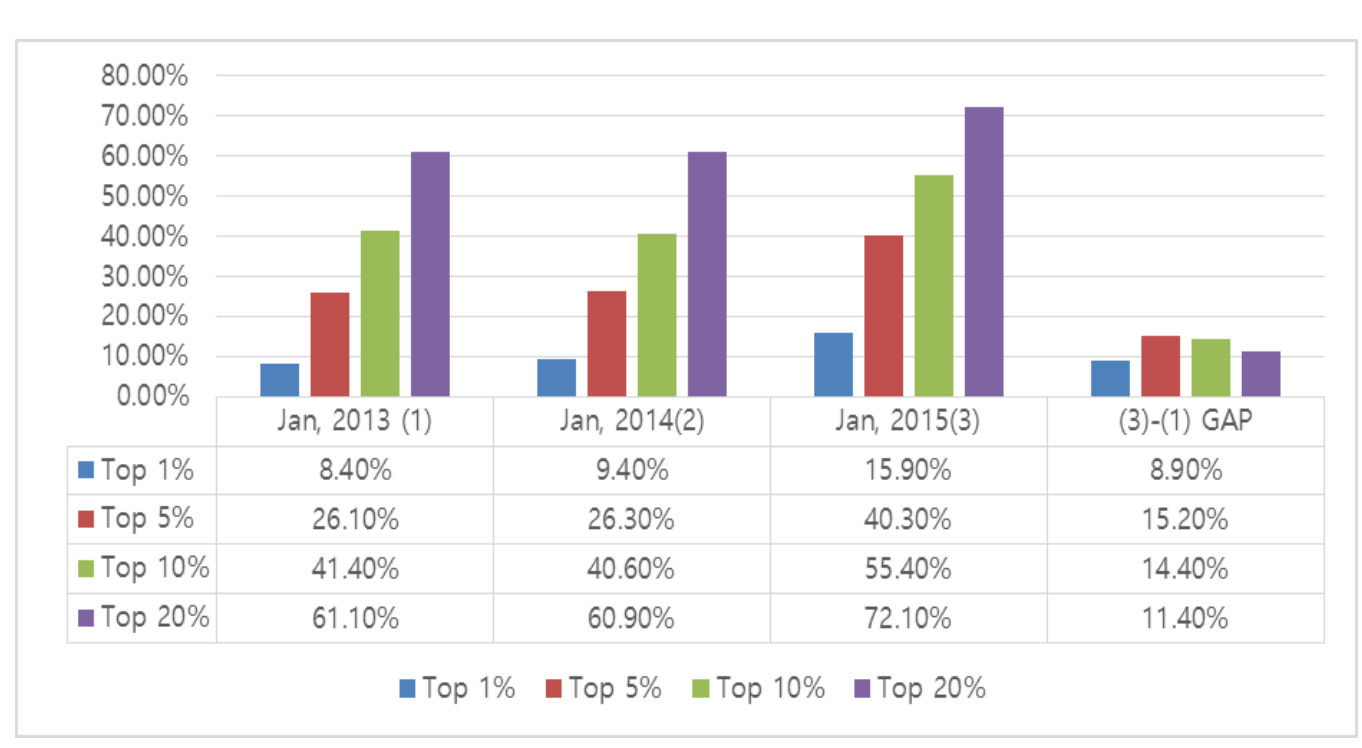

Figure 2. High Consumption Mobile Data User Group Traffic Usage Traffic for Each Year for 4G Network Service (KT) 


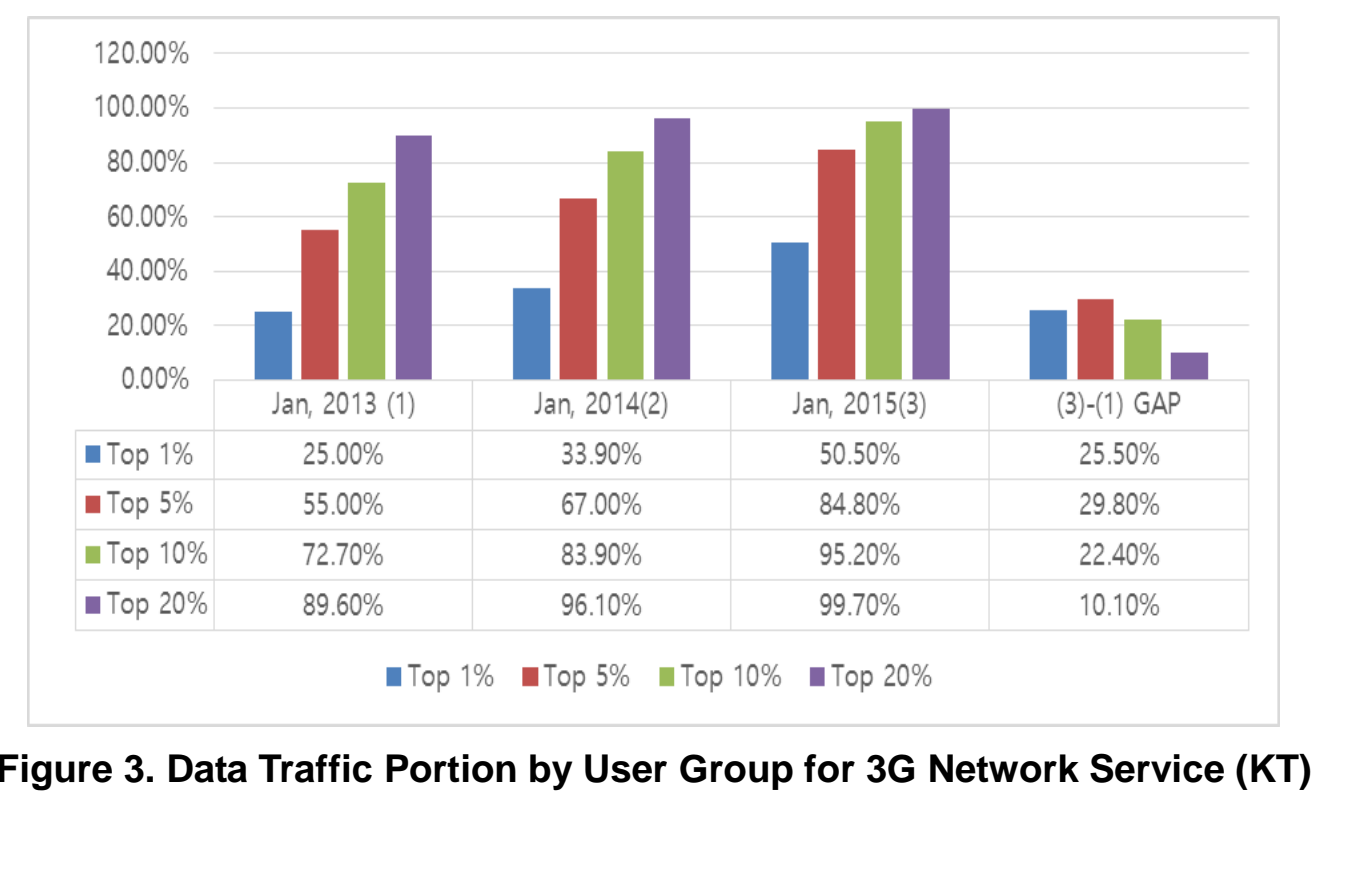

\subsection{The Pattern of Data Traffic by a Mobile Heavy User Group}

It is raised 2.3 times up in March 2015 contrast to March 2013 about contents usage traffic caused by LTE Data bandwidth @dvance.

The reasons of growth for contents usage are quite diverse, such as diversity of mobile contents floods, device development and mobile bañdwidth evolution.

It is increased for mobile traffic led by vast bulk contents rise; such as video, game or streaming music. Various SNS diffusion 1s another element which leads mobile traffic, but Web-portal usage and Mobile App downloads relatively decreased from past (Figure 4).

The SNS and video,Play are supposed to be increased as per mobile podcast spread and various SNS Services create huge data traffic from now on. In addition, huge content through Cloud seyvice transter gets commonly operated in the market. 


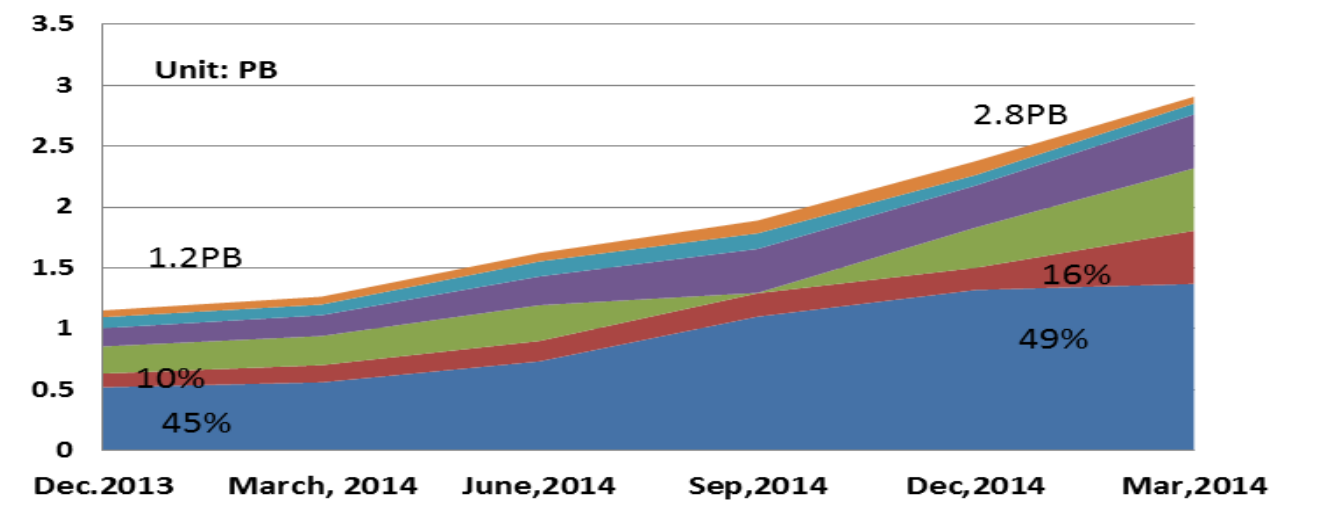

- Video Mulitmedia Web-Portal $\square$ SNS App Download

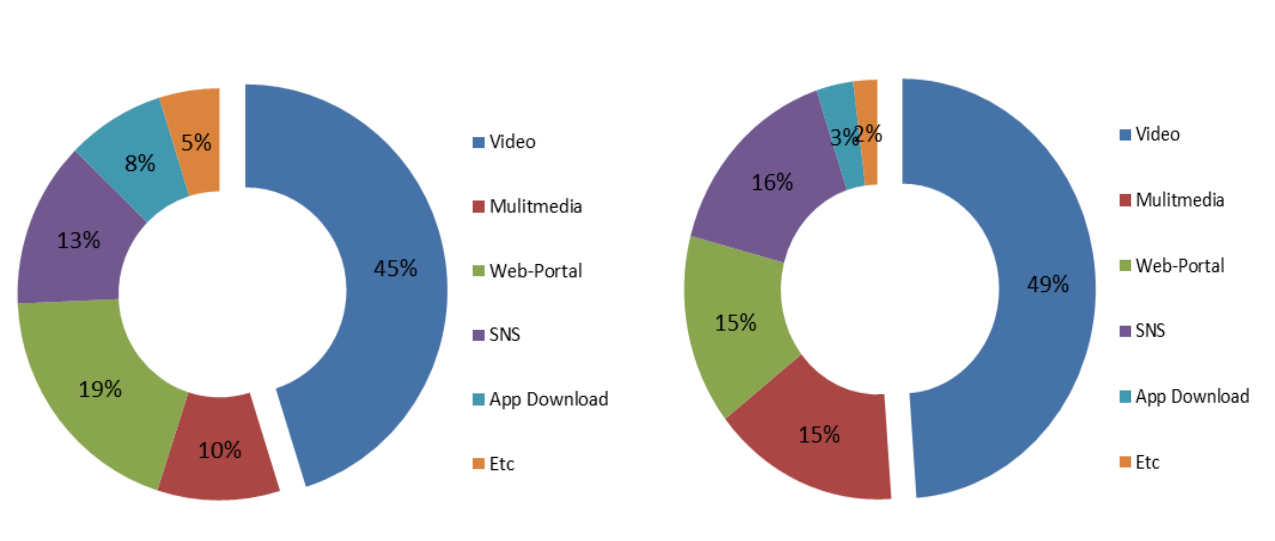

March, 2013: $12 \mathrm{~PB}$

March, 2015: 2.4PB

Figure 4. Data Trafific for Contents Usage by Year (Ministry of Science ICT and Future Planning)

\subsection{The Correlation Between Broadband Internet and Mobile Traffic Growth}

It is available to find out that the share of mobile traffic by heavy user is grown up for mobile data traffic. Then it is required to research about Broadband Internet service traffic by each user groups.

The share of broadband traffic declined a bit while mobile traffic has grown. It means that the-user groups are moving from broadband internet service to mobile internet data service, especially into a smartphone (Figure5), and the share of broadband service traffic for $20 \%$ heavy user group has been down sharply, compared with $1 \%$ heavy user group. In fact, the mobile traffic and broadband internet service is inversely proportion (Figure6). And it seems that the gap of traffic gets shrinked in matured market circumstance, but it was further in growing market.

As though mobile data traffic is dramatically increasing, we can see that the weekly internet usage time has been slightly decreasing(Figure7).

However, Internet usage time of both heavy user group and light user group is increasing from 2010 when smartphone has been introduced (Figure8). 


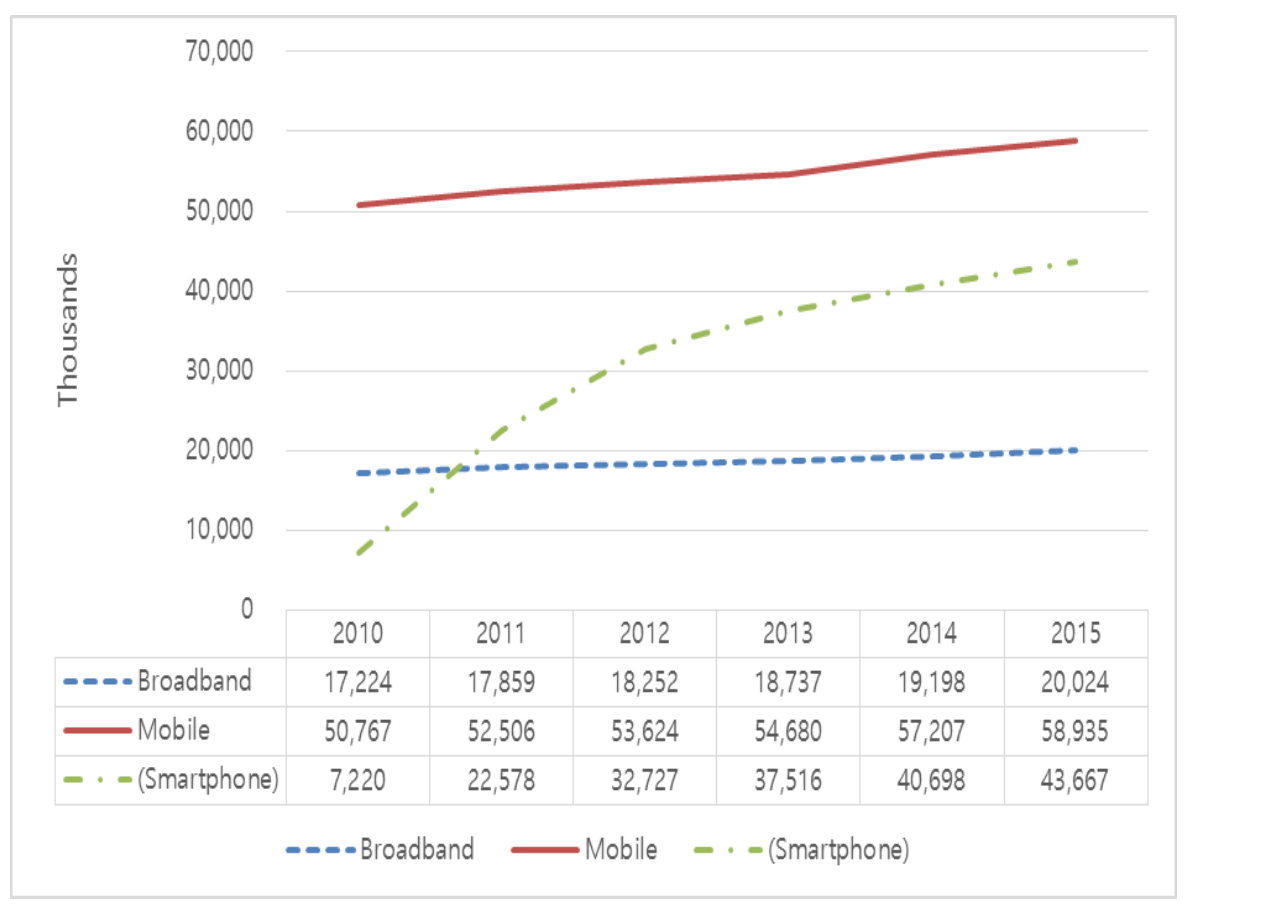

Figure 5. Broadband and Mobile Subscribers lincluding Smartphone. (KISA,

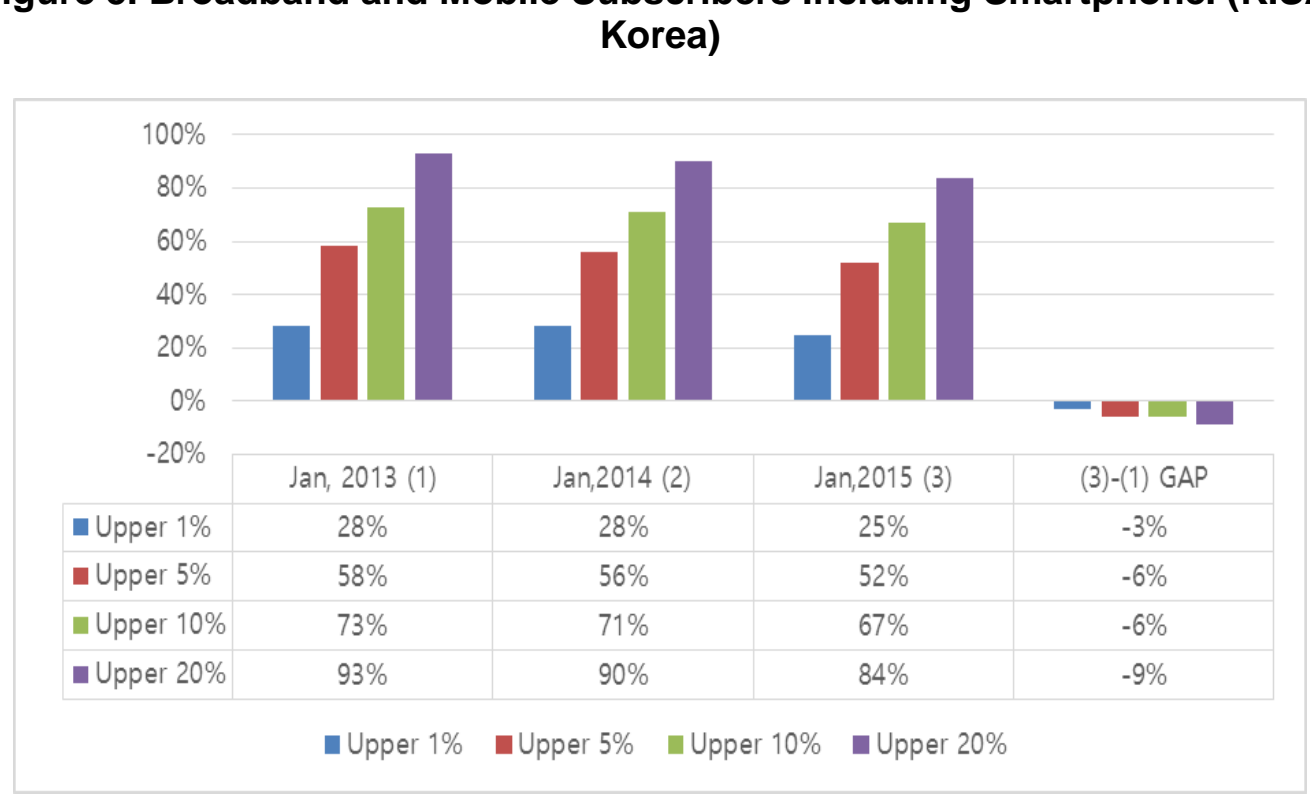

Figure 6. Broadband Internet Traffic by Heavy User for Each Year. (KT, Sampling Data) 


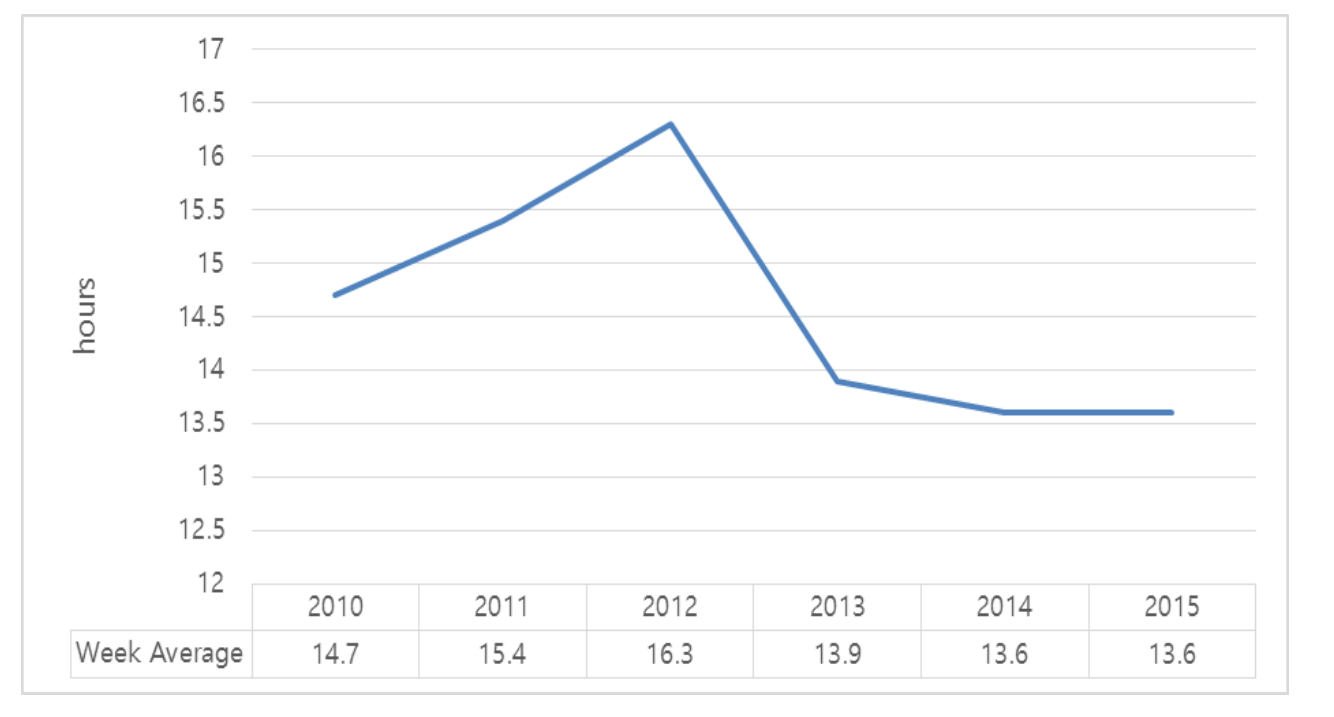

Figure 7. Weekly Internet Usage Time (Including Mobile) Per Internet Users (KISA, Korea)

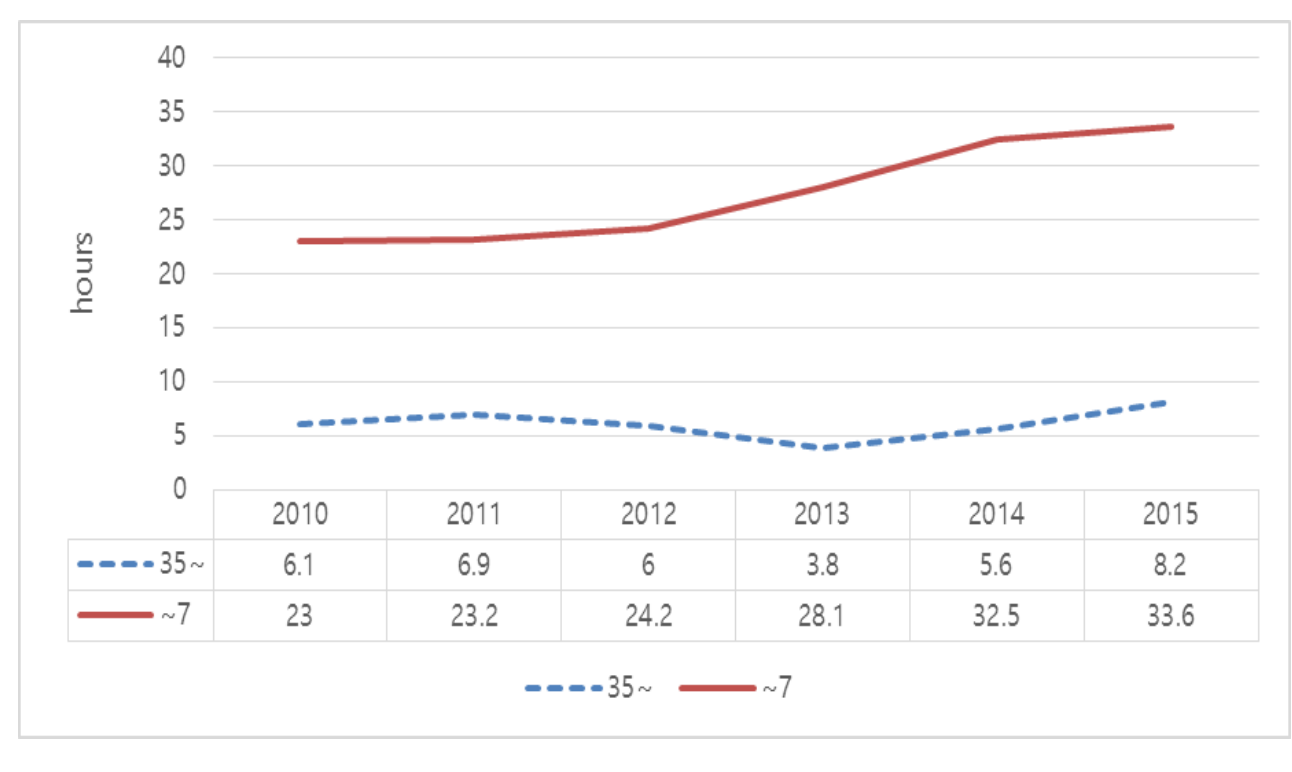

\section{Figure 8. Weekly Internet Usage Time Change (Including Mobile) Between Heavy User Group and Light Group (KISA, Korea)}

\subsection{Perspective of IoT (M2M) Industry Development}

The IoT devices are totally 860,000 EA, it charges $5 \%$ for total mobile devices. Most devices are operating $3 \mathrm{G}$ network $(96.5 \%)$. It is the fastest-growing market. The main use is wireless security device (34.2\%), and Vehicle management is $22.6 \%$, mobile payment is $13.5 \%$ and public transportation system charges $10.9 \%$ among IoT use.

According to the "Gartner Research" (Global Market Research Firm), it is supposed to reach 4,900,000,000 devices of IoT service by this year, and 25,000,000,000 devices are used until 2020 in global market. Also the budget is USD 69 billion from this year to USD 263 billion to 2020. It is tremendously raised next ages.

It is predicted that IoT industry is main stream among IT market in 2020. A lot of ICT firms, such as Google, Apple or CISCO concerned about IoT Service, then IoT traffic 
should be sharply grown. While Ordinary device increased 6T up, otherwise, IoT device has grown $20 \%$ up.

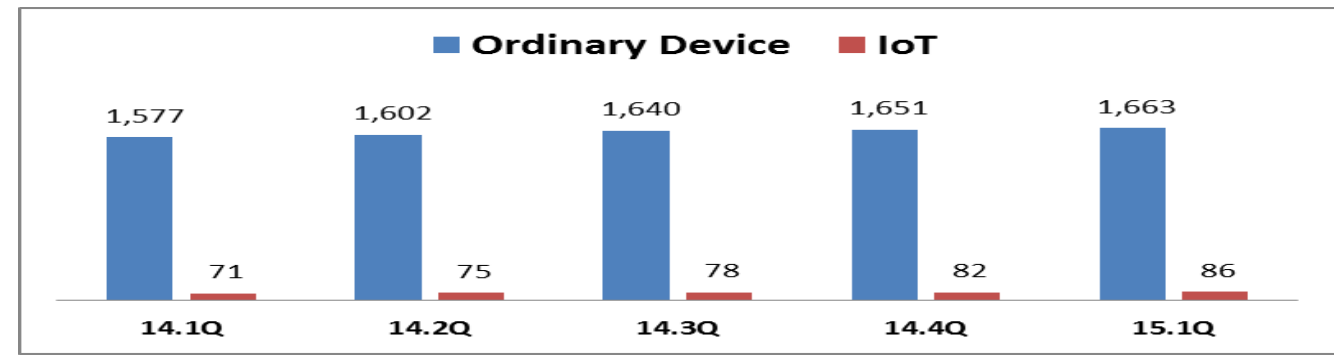

Figure 9, loT Device Portion Among Ordinary Devices (KT)

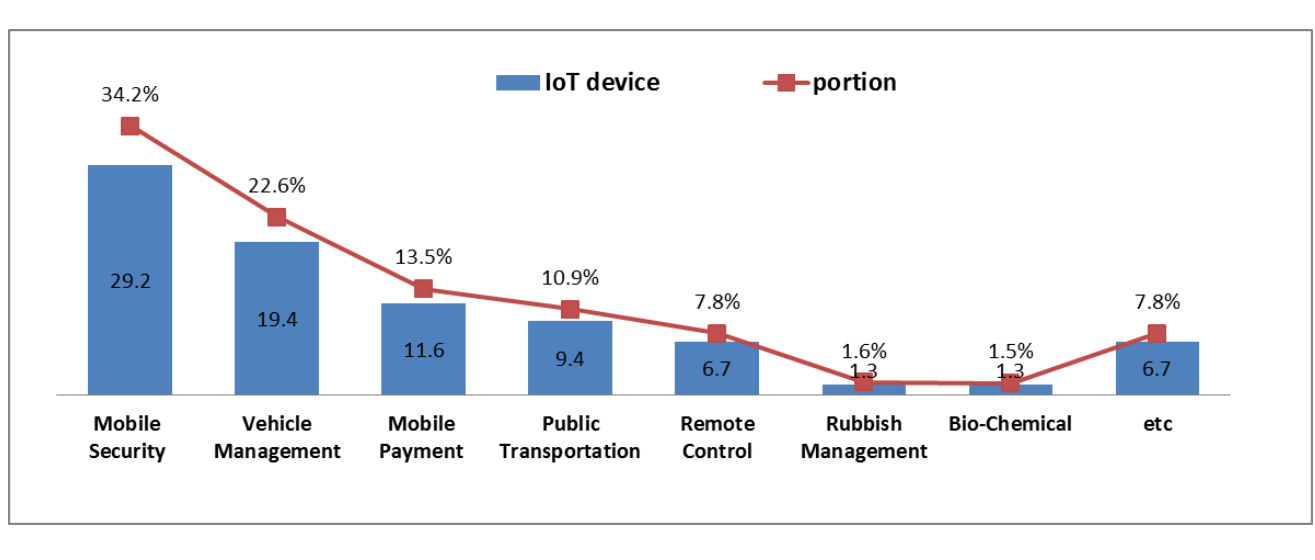

Figure 10. IoT devicge Usage State (KT)

\section{Conclusions}

According to S-curve Digital Divide Theory, it is regarded as significant factor about Gap between each user group in mobile tech has been matured enough. It is found how "Smart Divide" has appeared and expanded. First, Polarization of mobile use group usage has progressed rapidly while mobile data tariff diversity, it also results the occupation growth of heavy aser group. Second, The Polarization of mobile user group has not occurred in case of mobile data equality caused by feasibility of mobile access for anyone and network deyelopment. Third, the gap of usage gets diminished in matured market circumstance between each user groups, such as broadband market. On the other hands, the gap of usage is getting further growing market, such as mobile market. In this study, it was not clearly clarified for the reason why mobile data usage gap by each user groups is extended as data usage availability development. However, it might be a compound phenomenon. Huge data multimedia service expansion, diverse entertainment contents economical business user and generation mobile data needs of difference generations are main reasons for this phenomenon. We may have further study to clarify the distinct reason by category of user service and pattern. Additionally, new IoT era is regarded as most critical issue for coming mobile market also affects data usage gap between diverse use groups. It is required to more in-depth study for use group service usage pattern and market environment factors 


\section{Appendix (Result of Survey on the Internet Usage in Korea)}

Hours of use of the Internet by gender \& age from KISA, Korea, 2015 (unit: hours)

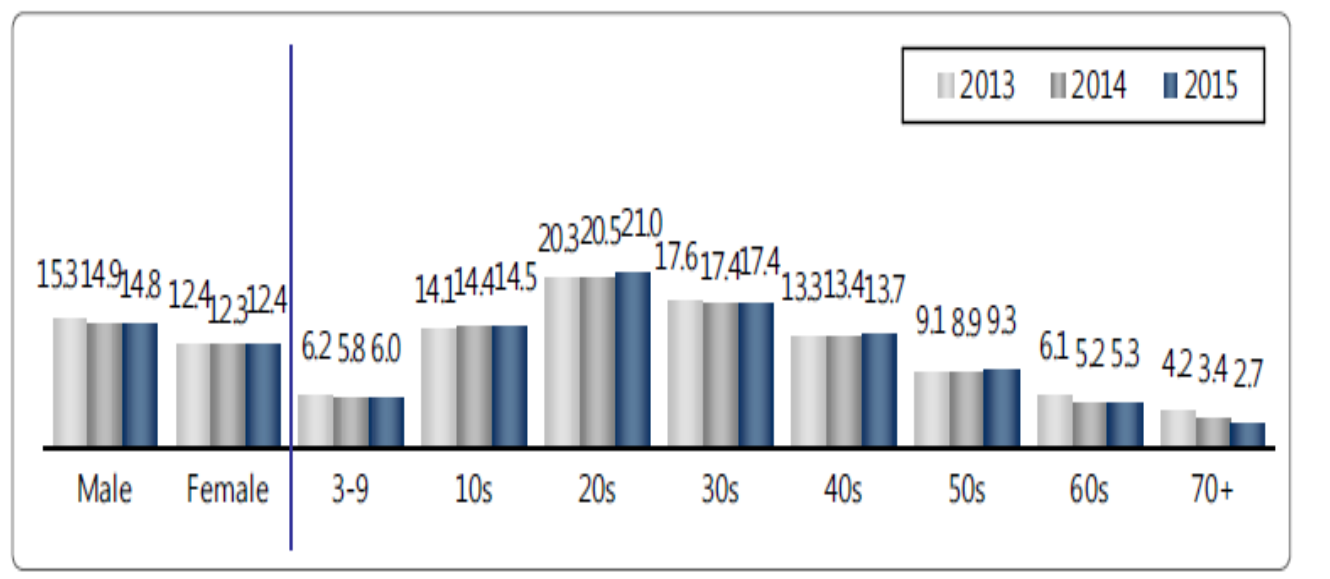

Household with ICT Devices (Multiple Response) from KISA, Korea, 2015

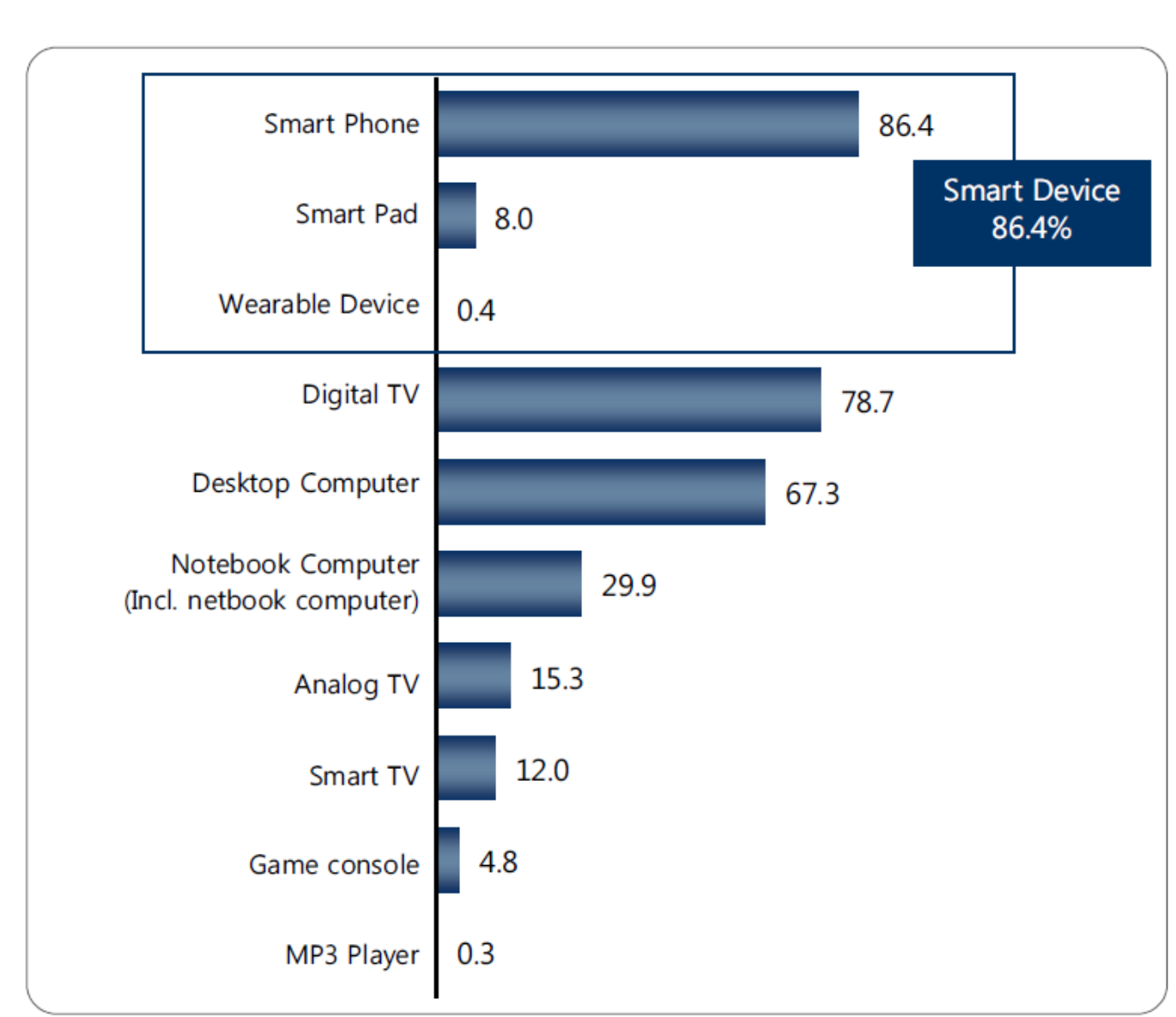

Internet Access Device (Multiple Responses)-Internet Accessible Household from KISA, Korea, 2015 


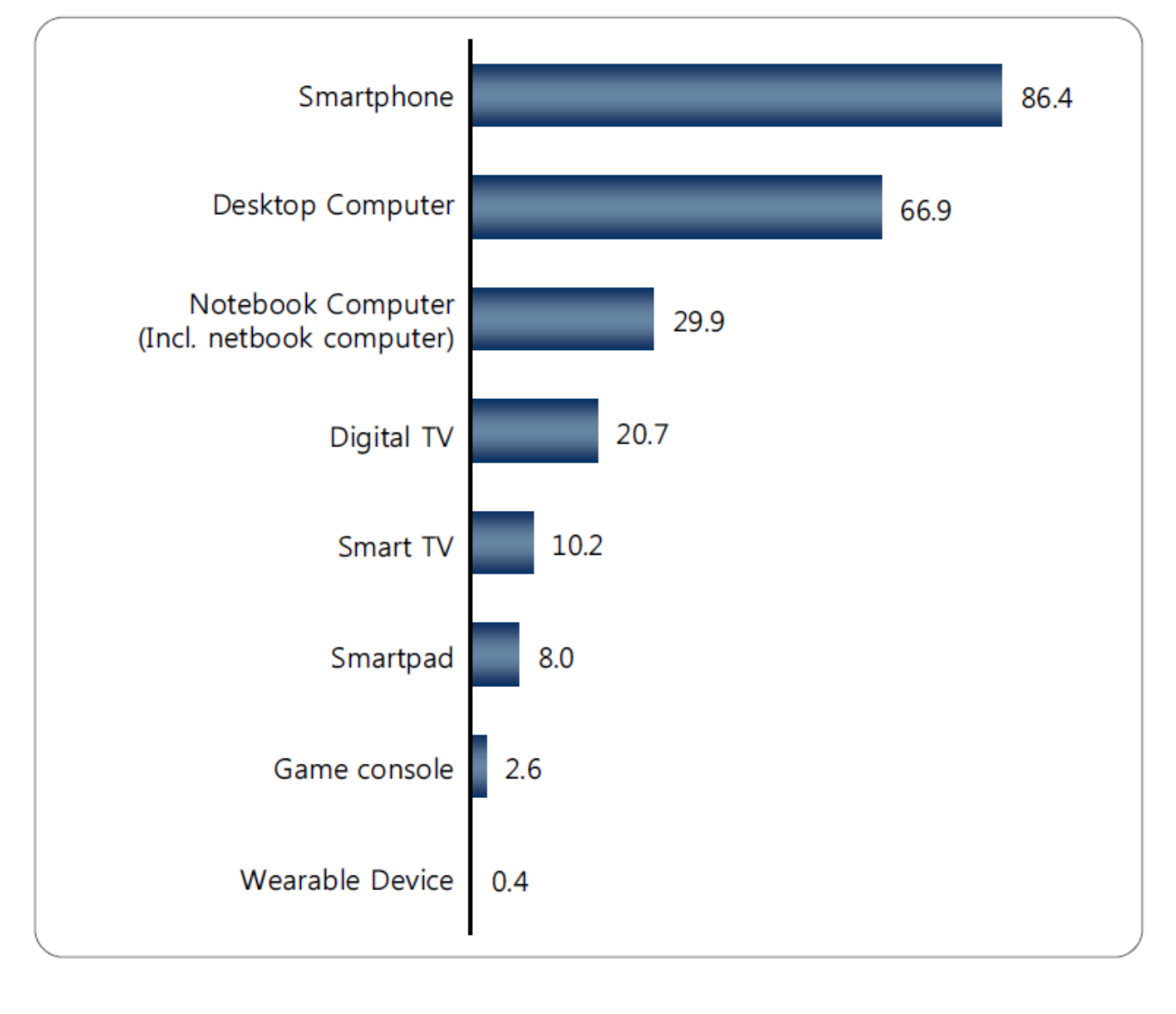

\section{References}

[1] "A Study on Digital Divide of Aged Women", Korean mobile research institute, (2007).

[2] "Information Society Szilard Molnar', The explanation frame of the digital divide, (2002).

[3] S. Jung and C. Y. Jung, "The ate system of Internet Network based on Internet traffic alternation", Journal of Information and Communication Convergence Engineering, vol. 1, (2014), pp. 1-10.

[4] D. Kim, Y Lee and S. Ahn "The control of network flood for multimedia in mobile network", Journal of Information and Communieation Convergence Engineering, (2009), pp. 1411-1421.

[5] G. Jung and E. Lee "Congestion Control Scheme for Efficient”, Journal of Information and Communication Convergence Engineering, (2014), pp. 1599-1609.

[6] J. H. Lee, "Socio-denographic gaps in mobile use, causes, and consequences: a multi-group analysis of the mobile divide model", Information, communication \& Society, vol. 17, no. 8, (2013).

[7] K. Brown "Mobile Phones Bridging the Digital Divide for Teens in the US", University of Michigan, (2011).

[8] C. Gilleard, I. Jones and P. Higgs, "Connectivity in Later Life: the Declining Age Divide in Mobile Cell Phone Ownership", Sociology Research Online, vol. 20, no. 2, (2013), pp. 3.

[9] J. ames, "Sharing mobile phones in developing countries: Implications for the digital divide", (2013).

[10] Y. E. Pearce and R. E. Rice, "Digital Divides From Access to Activities: Comparing Mobile and Personal Computer Internet Users", (2014).

[11] K. Chan, A. H. and S. N. Tsang, "Usage of mobile phones amongst elderly people in Hong Kong”, In Proceedings of the International Multi Conference of Engineers and Computer Scientists, vol. 2, (2013), pp. 1016-19.

[12] K. E. Pearce and R. E. Rice, "Divide and diffuse: Comparing digital divide and diffusion of innovations perspectives on mobile phone adoption", (2012).

[13] T. Kalderon and E. Wright, "Older adults: Are they ready to adopt health related ICT", International Journal of Medical Informatics, vol. 82, no. 11, (2013), pp. 209-231. 


\section{Authors}

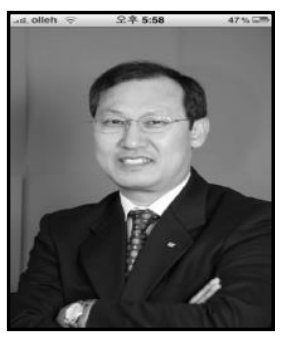

Hongjae Lee, received his Master`s Degree in Statistics from Seoul National University in Korea, (1985). He worked in the IT field as a researcher and manager over 30 years. Now he is an executive vice president of KT Co., LTD. since 2012.

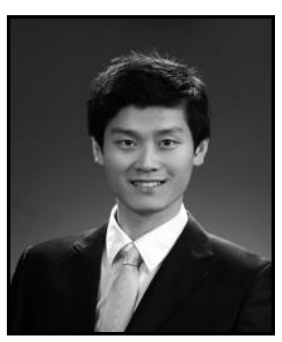

Sang-won Kim, received his Bachelor's Degee in Public administration in Yonsei University (2012). He has worked in ICT Management since 2012. Now he is a manager in KT. He is interested in ICT Consulting for Global dompany

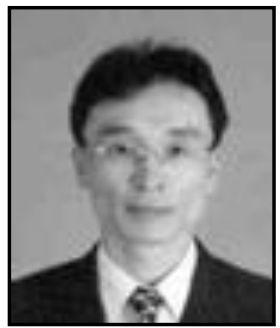

Jong-Bae Kim, received his Bachelor's Degree in Business Administration in Qniversity o Seoul, Seoul (1995) and Master's Degree (2002) Dóctor's Degreé in Computer Science in Soongsil University Seoul(2006). Now he is a professor in the Graduate School of Software, Soongsil University, Seoul, Korea. His research interests focus on Software Engineering, and Open Source Software.

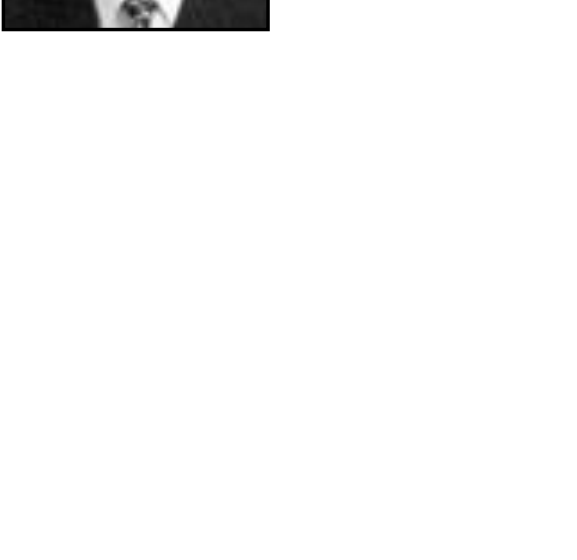


International Journal of Multimedia and Ubiquitous Engineering

Vol.11, No.8 (2016)

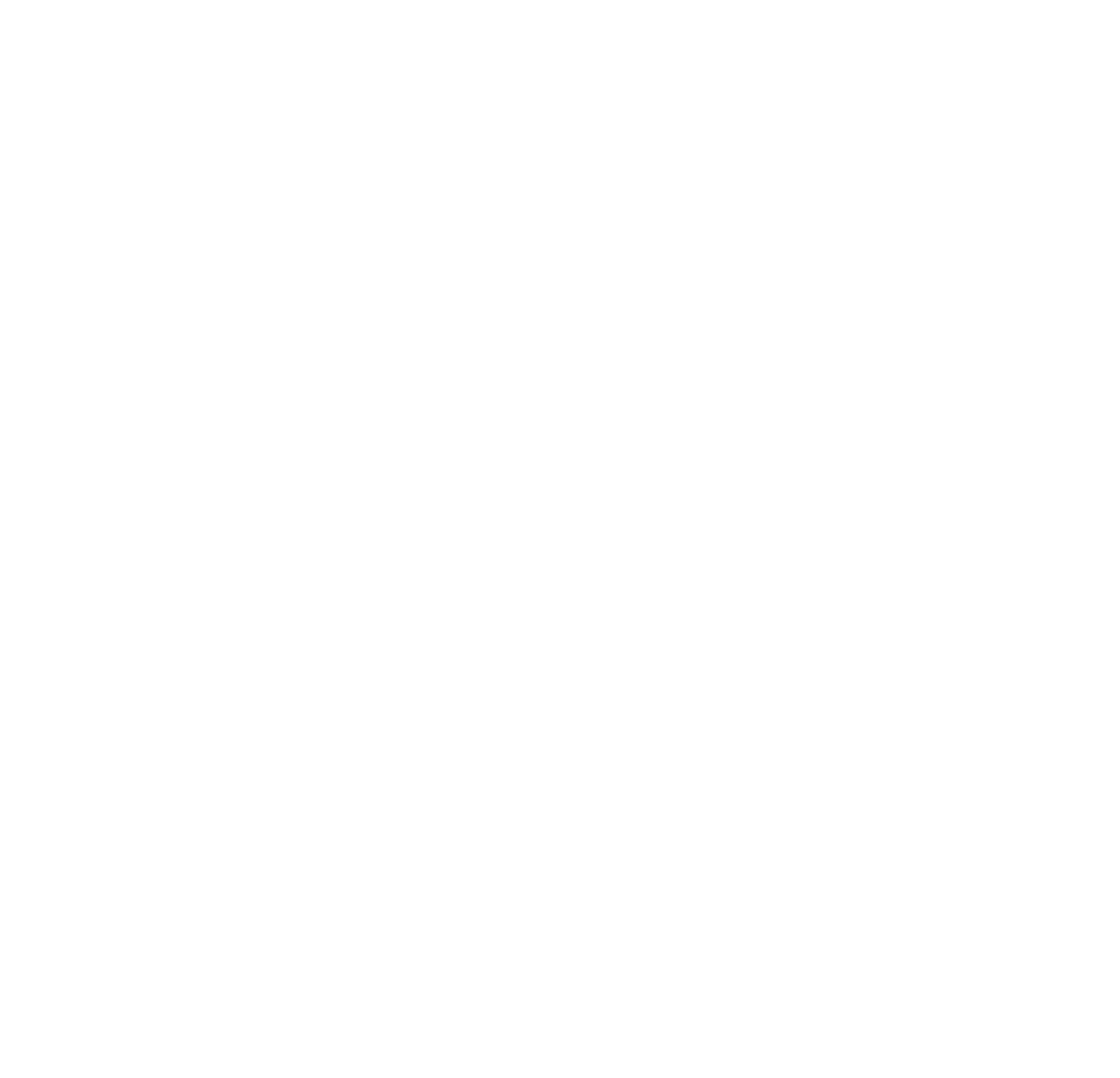

